\title{
Study of perinatal outcome in twin gestation in rural referral hospital in Maharashtra (India): a cross sectional study
}

\author{
Mahesh Asalkar, Bijal Kasar*, Swapnil Dhakne, Patit Paban Panigrahi
}

Department of Obstetrics and Gynecology, MIMER Medical College, Talegaon (D) Pune, Maharashtra, India

Received: 05 September 2017

Accepted: 29 September 2017

*Correspondence:

Dr. Bijal Kasar,

E-mail: bijal.mistrykasar85@gmail.com

Copyright: () the author(s), publisher and licensee Medip Academy. This is an open-access article distributed under the terms of the Creative Commons Attribution Non-Commercial License, which permits unrestricted non-commercial use, distribution, and reproduction in any medium, provided the original work is properly cited.

\begin{abstract}
Background: Incidence of twin pregnancy is increasing all over the world. It can occur after Assisted Reproductive Technology (ART) or spontaneously and associated with increased maternal and neonatal complications both in the developed and developing countries.

Methods: A descriptive (Cross sectional) study of 64 cases of twins was undertaken between January 2013 till December 2015. Data collection was done prospectively from the patients admitted to the hospital with twin gestation. Inclusion criteria: All pregnancy with twin gestation more than 28 weeks of gestation. Twin pregnancies with both fetuses alive are included. Exclusion criteria is multiple gestation other than twins, cases with congenital malformation and intrauterine death (in one or both twins) were excluded. Data included thorough antenatal history, demographic details and intrapartum and postpartum maternal and neonatal details.

Results: Prevalence of twins in our study was $1.61 \%$ (95\% CI 1.3-2\%). Out of 69 cases of twin pregnancy 64 cases fulfilled the inclusion criteria. History of ovulation induction was associated with $23 \%$ cases. Commonest complications observed were preterm labour (56.5\%) anaemia (43.4\%) and PIH (22.3\%). 30.2\% cases delivered vaginally whereas $69.8 \%$ patients required c. section, malpresentation being commonest indication. No intrapartum still birth was recorded. Early neonatal death was seen in eight cases, causes were prematurity, hyaline membrane disease and neonatal jaundice. Diamnoitic-dichorionic twins were $90 \%$ and $3 \%$ cases were monoamniotic monochorionic. Zygosity was calculated by Weinbergs formula and $84 \%$ cases were dizygotic while $16 \%$ cases were monozygotic. No maternal mortality related to twin pregnancy was reported in present study.

Conclusions: All twin pregnancy should be considered as high risk pregnancies and should have mandatory hospital delivery. Early diagnosis, adequate antenatal, intrapartum and postpartum care as well as good NICU back up are the key factors in reducing the complications and improving the perinatal outcome in twin pregnancies.
\end{abstract}

Keywords: Pregnancy outcome, Preterm delivery, Twin pregnancy

\section{INTRODUCTION}

Twin is a type of multiple birth in which the mother gives birth to two offspring from the same pregnancy. Incidence of twin pregnancy is increasing all over the world. It can occur after Assisted Reproductive Technology (ART) or spontaneously. It occurs one in 80 pregnancies globally. ${ }^{1-3}$ The prevalence of spontaneous twin pregnancies ranges from approximately $0.6 \%$ of pregnancies in Asia and 1-2\% in Australia, Europe and the United States of America (USA) to about 4\% in Africa. ${ }^{4}$

Neonatal mortality rate is five to six times higher than that of singleton pregnancy. ${ }^{5}$ (4) The main causes of adverse neonatal outcomes in multiple pregnancies are related to prematurity, fetal growth restriction and low birth weight. ${ }^{6}(5)$ Though maternal deaths related to twin 
gestation is on the decline, maternal morbidity in terms of Anemia, preterm labour, Preeclampsia, Ante partum hemorrhages, increased rates of caesarean section and PPH are still very high. ${ }^{7}$ Hence periodic review of the outcome of twin pregnancy is necessary to scale up efforts aimed at reducing associated complications. The objective of this study was to know the incidence of twin in the tertiary care hospital, to study high risk factors associated with twin pregnancies and to describe the maternal and perinatal outcome in twin pregnancies delivered at a tertiary hospital.

\section{METHODS}

Descriptive (Cross sectional) study was conducted at MIMER Medical college from January 2013 to December 2015.Out of 69 twin deliveries 64 satisfied the inclusion criteria and are included in the study.

\section{Inclusion criteria}

- Patients with twin pregnancy beyond 28 weeks of gestation and delivered at study institution.

- Patients where neonatal follow up to one week of life was available.

\section{Exclusion criteria}

- Multiple gestation other than twins were excluded.

- Cases with congenital malformation which are incompatible with life (in one or both twins) and intrauterine death of either or both of twins were excluded.

\section{Data collection}

Data was collected in a uniform, consistent and reliable manner by trained qualified doctors with the use of standard proforma. Key variables such as age, parity, duration of gestation, physical examination, mode of delivery antepartum, intrapartum and postpartum complications was tabulated. Previous obstetric history and history of infertility treatment (ovulation induction), use of any oral contraceptive prior to conception was noted. Results of routine and specialized investigations and ultrasonography were recorded. After delivery and caesarean section placental morphology was studied in detail particularly taking note of number, type and weight of placenta. To determine the type of placenta, the relationships of membranes were carefully studied. Maternal and neonatal morbidity and mortality upto one week of post delivery was recorded.

\section{Data management}

Stringent quality assurance measures were followed at various stages of data handling so as to ensure completeness, accuracy and reliability of the data. Data entry and consistency check were done manually.

\section{Statistical analysis}

Statistical analysis was done using Epi-info7 software.

\section{RESULTS}

Table 1 shows most of our patients were in the age group of $31-35(40.7 \%)$. Majority of cases around the age of 30 years (67\% cases in $25-35$ age group).

Table 1: Demographic variables in the study.

\begin{tabular}{|lll|}
\hline Socio demographic variable & No. of cases & $\%$ \\
\hline Age & \multicolumn{2}{l|}{} \\
\hline$<20$ years & 2 & 3.1 \\
\hline $21-25$ & 14 & 21.9 \\
\hline $26-30$ & 17 & 26.6 \\
\hline $31-35$ & 26 & 40.6 \\
\hline$>35$ & 5 & 7.8 \\
\hline Gestational age & & \\
\hline $28-31.6$ & 7 & 10.9 \\
\hline $32-34.6$ & 10 & 15.6 \\
\hline $35-36.6$ & 19 & 29.7 \\
\hline$\geq 37$ weeks & 28 & 43.8 \\
\hline Parity & & \\
\hline Primi & 28 & 43.8 \\
\hline Multi & 36 & 56.3 \\
\hline Occupation & & \\
\hline Housewife & 40 & 62.5 \\
\hline Employed & 13 & 20.3 \\
\hline Farmer & 11 & 17.2 \\
\hline Educational status & & \\
\hline Illiterate & 02 & 3.1 \\
\hline$<8^{\text {th }}$ Std. & 08 & 12.5 \\
\hline $8-12^{\text {th }}$ Std & 19 & 29.7 \\
\hline Graduation & 29 & 45.3 \\
\hline Post graduation & 06 & \\
\hline & & \\
\hline
\end{tabular}

$43.6 \%$ patients were delivered after 37 weeks indicating high prevalence of preterm deliveries $(56.4 \%)$ in twin gestation. Most of our patients were (56\%) were multigravidas and $62.5 \%$ were housewife. Most of our patients were having education upto graduation (46\%).

Table 2: Risk factors association.

\begin{tabular}{|lll|}
\hline Risk Factor & Cases & $\begin{array}{l}\text { Percentage } \\
(95 \% \mathrm{CI})\end{array}$ \\
\hline $\begin{array}{l}\text { OCP use prior to current } \\
\text { pregnancy }\end{array}$ & 5 & $7.8(2.9-16.5)$ \\
\hline Family history of twinning & 6 & $9.4(3.9-18.5)$ \\
\hline $\begin{array}{l}\text { History of treatment for } \\
\text { infertility }\end{array}$ & 15 & $23.4(14.3-35.0)$ \\
\hline Age (26-35) & 43 & $67.2(55.0-77.8)$ \\
\hline Parity (Multiparity) & 36 & $56.3(44.0-68.0)$ \\
\hline
\end{tabular}

Table 2 shows association of various factors such as OCP use prior to current pregnancy in $7.8 \%$ cases, family 
history of twinning in $9.2 \%$ cases and h/o infertility treatment was noted in $23 \%$ of cases.

Table 3: Distribution of patients by fetal presentation.

\begin{tabular}{|lll|}
\hline Presentation & Number & $\begin{array}{l}\text { Percentage }(95 \% \\
\text { CI) }\end{array}$ \\
\hline $\begin{array}{l}\text { Vertex-Vertex } \\
\text { Vertex-Breech }\end{array}$ & 33 & $51.6(39.4-63.6)$ \\
\hline $\begin{array}{l}\text { Vertex- } \\
\text { Transverse }\end{array}$ & 01 & $15.6(8.2-26.1)$ \\
\hline Breech-Vertex & 12 & $1.6(0.08-7.5)$ \\
\hline Breech-Breech & 08 & $18.8(10.6-29.7)$ \\
\hline $\begin{array}{l}\text { Breech- } \\
\text { Transverse }\end{array}$ & 00 & 0.0 \\
\hline
\end{tabular}

Table 3 shows commonest presentation was vertex-vertex in $52.6 \%$ cases followed by breech-vertex in $18.4 \%$ cases and vertex-breech in $15.7 \%$ cases. Table 4 shows various complications observed in present study participants such as preterm labour was commonest in $56.5 \%$, followed by anaemia in $43.4 \%$ cases and PIH in $22.3 \%$ cases, other complications such as IUGR, placenta previa, PROM, abruptio placentae and polyhydromnios have been reported as mentioned in table.

Table 4: Complications encountered by mothers.

\begin{tabular}{|c|c|c|}
\hline Maternal outcome & Number & $\begin{array}{l}\text { Percentage } \\
(95 \% \text { CI })\end{array}$ \\
\hline Preterm labour & 36 & $56.3(44-68)$ \\
\hline Anaemia & 28 & $43.8(32-56.1)$ \\
\hline $\mathrm{PIH}$ & 14 & $21.9(13-33.2)$ \\
\hline PROM & 11 & 17.2(9.4-27.9) \\
\hline GDM & 02 & $3.1(0.5-9.9)$ \\
\hline IUGR & 09 & $14.1(7.1-12.2)$ \\
\hline Placenta previa & 06 & $9.4(3.9-18.5)$ \\
\hline Abruptio placentae & 02 & $3.1(0.5-9.9)$ \\
\hline Polyhydromnios & 03 & $4.7(1.2-12.2)$ \\
\hline No complications & 18 & $28.1(18.2-40.0)$ \\
\hline
\end{tabular}

Table 5: Distribution by mode of delivery.

\begin{tabular}{|lllllll|}
\hline Mode of delivery & Twin 1 & $\%$ & Twin 2 & $\%$ & Total & $\%(95 \%$ CI) \\
\hline Spontaneous vaginal & 13 & 20.3 & 09 & 14.1 & 22 & $17.2(11.4-24.5)$ \\
\hline Assisted breech & 03 & 4.7 & 05 & 7.8 & 08 & $6.3(3-11.5)$ \\
\hline instrumental & 04 & 6.3 & 05 & 7.8 & 09 & $7.0(3.5-12.5)$ \\
\hline LSCS & 44 & 68.8 & 45 & 70.3 & 89 & $69.5(61-77)$ \\
\hline
\end{tabular}

Vaginal deliveries (including Assisted breech and instrument) $=19$; LSCS $=45$ (One patient required LSCS for $2^{\text {nd }}$ twin after first baby born vaginally) hence LSCS was required in 44 cases for $1^{\text {st }}$ twin and for 45 cases in $2^{\text {nd }}$ twin.

Table 5 shows 64 cases of twins gave birth to 128 babies, out of 128 babies $20.3 \%$ of $1^{\text {st }}$ twin had spontaneous vaginal delivery and $14 \%$ of $2^{\text {nd }}$ twin had spontaneous vaginal delivery. $4.6 \%$ of first twin were delivered by assisted breech and $7.8 \%$ of second twin had assisted breech delivery.

Instrumental (Forcepts/Vacuum) was required in $6.2 \%$ cases of first twin and $7.8 \%$ cases of second twin.

Number of assisted breech as well as instrumental delivery were more observed in second twin, indicating more requirement of skilled techniques and manoeuvres for delivering the second twin. $69.5 \%$ cases required LSCS for delivery and in one case c. section was required for $2^{\text {nd }}$ baby of twin where first has delivered vaginally.

Table 6 shows $84.4 \%$ cases were monozygotic and $15.6 \%$ cases were dizygotic calculated by Weinbergs formula.

$90.6 \%$ cases were diamniotic-dichorinoic and mono amniotic-monochorionic combination was seen in $3.12 \%$ cases. Male to female $(65: 63)$ ratio in present study was 0.97:1 with slight higher preponderance of female fetuses in twins.
Table 6: Sex combination, chorionicity and zygosity.

\begin{tabular}{|c|c|c|}
\hline $\begin{array}{l}\text { Twin delivery } \\
\text { variable }\end{array}$ & Number & $\%(95 \%$ CI $)$ \\
\hline \multicolumn{3}{|l|}{ Sex combination } \\
\hline Male-male & 18 & $28.1(18.2-40)$ \\
\hline Female-female & 19 & $29.7(19.5-41.7)$ \\
\hline Male-female & 15 & $23.4(14.3-35)$ \\
\hline Female-male & 12 & $18.8(10.6-29.7)$ \\
\hline \multicolumn{3}{|l|}{ Chorionicity } \\
\hline Dichorionic diamniotic & 58 & $90.6(81.5-96.1)$ \\
\hline $\begin{array}{l}\text { Diamniotic } \\
\text { monochorionic }\end{array}$ & 04 & $6.3(2-14.4)$ \\
\hline $\begin{array}{l}\text { Monochorionic } \\
\text { monoamniotic }\end{array}$ & 02 & $3.1(0.5-9.9)$ \\
\hline \multicolumn{3}{|l|}{ Zygosity } \\
\hline Monozygotic twins & 10 & $15.6(8.2-26.1)$ \\
\hline Dizygotic twins & 54 & $84.4(73.9-91.8)$ \\
\hline
\end{tabular}

Like sex twins: $18+19=37(57.8 \%, 95 \%$ CI $45.5-69.4 \%))$; unlike sex twins: $15+12=27(42.2 \%, 95 \%$ CI, 30.6-54.5\%)

Table 7 shows perinatal parameters of the neonates, $\left(1^{\text {st }}\right.$ twin versus 2nd twin) low APGAR at 1 min $(4.6 \%$ Versus $9.3 \%)$ and at $5 \mathrm{~min}(1.5 \%$ Versus $6.2 \%)$ as well as NICU requirement (36\% Versus $59 \%)$, all were more common 
in 2nd twin than first twin. Also, neonatal death was seen among 6 cases of $2^{\text {nd }}$ twin as compared to only 2 cases in $1^{\text {st }}$ twin. There was no still birth reported in our study. There was no maternal mortality seen in present study. 3
(4.7\%) pairs out of 64 pairs of twin showed discordant growth in the birth weight (Birth weight difference more than $15 \%$ ).

Table 7: Perinatal outcome (morbidity and mortality).

\begin{tabular}{|c|c|c|c|c|c|c|c|}
\hline \multicolumn{2}{|c|}{ Neonatal outcome } & $\begin{array}{l}\text { Number } \\
\left(1^{\text {st }} \text { twin }\right)\end{array}$ & Percentage & $\begin{array}{l}\text { Number } \\
\left(2^{\text {nd }} \text { twin }\right)\end{array}$ & Percentage & Total & Percentage \\
\hline \multicolumn{2}{|c|}{ APGAR $<7$ At 1 minute } & 3 & 4.7 & 6 & 9.4 & 09 & $7.0(3.5-12.5)$ \\
\hline \multicolumn{2}{|c|}{ APGAR $<7$ at 5 minutes } & 1 & 1.6 & 4 & 6.3 & 5 & $3.9(1.4-8.4)$ \\
\hline \multicolumn{2}{|c|}{ Admission to NICU } & 23 & 35.9 & 37 & 57.8 & 60 & $46.9(85.6-98)$ \\
\hline \multicolumn{2}{|c|}{ Neonatal death in $1^{\text {st }}$ week } & 2 & 3.1 & 6 & 9.3 & 8 & $6.3(3-11.5)$ \\
\hline \multicolumn{2}{|c|}{ Birth weight $<2.5 \mathrm{~kg}$} & 38 & 59.4 & 43 & 67.2 & 81 & $63.3(54.7-71.3)$ \\
\hline \multirow{4}{*}{$\begin{array}{l}\text { B.w } \\
<2.5 \mathrm{~kg}\end{array}$} & $<1.0 \mathrm{~kg}$ & 3.1 & 3.1 & 03 & 4.7 & 05 & $3.9(1.4-8.4)$ \\
\hline & $1-1.5 \mathrm{~kg}$ & 9.4 & 9.4 & 07 & 10.9 & 13 & $10.2(5.8-16.3)$ \\
\hline & $1.5-2.0 \mathrm{~kg}$ & 15.6 & 15.6 & 11 & 17.2 & 21 & $16.4(10.7-23.6)$ \\
\hline & $2-2.5 \mathrm{~kg}$ & 31.3 & 31.3 & 22 & 34.4 & 42 & $32.8(25.1-41.3)$ \\
\hline \multicolumn{2}{|c|}{ Birth weight $>2.5 \mathrm{~kg}$} & 26 & 40.6 & 21 & 32.8 & 47 & $36.7(28.7-45.3)$ \\
\hline \multicolumn{8}{|c|}{ Neonatal mortality } \\
\hline \multicolumn{2}{|c|}{ Fresh still birth } & 0 & 0 & 0 & 0 & 0 & 0 \\
\hline \multicolumn{2}{|c|}{ Neonatal death } & 03 & 4.7 & 05 & 7.8 & 08 & $6.3(3-11.5)$ \\
\hline \multicolumn{2}{|c|}{ Cases with discordant growth } & $\begin{array}{l}3 \text { pai } \\
\text { more }\end{array}$ & . & $\begin{array}{l}\text { d discorc } \\
\text { iir. }\end{array}$ & rowth wit & & difference of \\
\hline
\end{tabular}

\section{DISCUSSION}

From prehistorical times, right up to the dawn of the new millennium, mankind has always been fascinated by the phenomenon of multiple pregnancy. Serious efforts have been made to unify all kinds of contribution on twins into a new branch of science named "Gamellology"

The female child is programmed by nature to monoovulate, to nurture one fetus and to take care of one neonate at a time. Recent advances in ovulation induction, diagnostic ultrasound and Assisted Reproductive Technologies (ART) have caused a new spurt in incidence of twin gestation.

The incidence of twin pregnancy varies widely throughout the world. The highest incidence has been reported in blacks of West African descent and the lowest in asian Mongolians. ${ }^{8,9}$ In this study the incidence of twin deliveries was $1.6 \%$. This was higher than reported in previous study carried out in India. The difference may be due to genetic influences, increased use of ovulation induction drugs and also more number of cases being referred to tertiary care center by nearby PHCs and private practitioners. Basirat et al found frequency of twins in 1.4 cases while another study by Kavehmahesh et al showed frequency of twinning in $1.8 \%$ cases. $^{10,11}$ Prevalance of twins was reported to be in 1 in 80 by Usta in United States, 1 in 48 births by Musili et al in Kenya and 1 in 43 births by Mutihir et al in Nigeria. ${ }^{9,12,13}$ In general, growing use of assisted reproductive technology is causing an increase in the prevalence of twin pregnancy throughout the world. ${ }^{12-14}$

Twin birth registries are rare in low and middle income countries(LMIC) and twin specific research is generally based on hospital based studies, secondary analyses of interventional trials or retrospective analyses of demographic and health survey (DHS) data, all with significant limitations and bias. ${ }^{15-17}$ In LMICs medical record documentation is suboptimal which may affect the data quality. ${ }^{16}$

Previous studies have shown increasing maternal age and parity have been found to be strongly associated with increased incidence of twinning. ${ }^{1,16,18}$ In present study $41 \%$ cases were in the age group of $31-35$, followed by $26 \%$ in the age group of 26-30. There is clustering of cases around the age of 30 , reflecting the increase in the postponement of pregnancy until the thirties as women increasingly pursue careers before childbearing. In present study $29 \%$ cases had their education till graduation and $21 \%$ were working women, this reflects increase priority towards education and career are associated with increased maternal age and indirectly may be associated with twinning due to increased maternal age.

Apart from maternal age, Parity have been found to be strongly associated with increased incidence of twinning. ${ }^{1,16,18}$ Most of our patients were multigravida $(56 \%)$. which corroborates with study of Chaudhary et al 
with figure of $64.2 \%$ for multigravida showing association with increased parity. ${ }^{19}$ Even higher frequency of $84.25 \%$ twinning in multigravida was reported by Spellacy et al. ${ }^{20}$ However age and parity together influence towards higher incidence of twinning or they contribute independently towards increased incidence of twinning is not studied and needs evaluation.

A number of factors apart from age and parity have been associated with increased incidence of twinning. These include use of fertility drugs for ovulation induction, family history of twinning, use of OCP prior to conception, maternal height ad weight, previous history of twin delivery and diet. ${ }^{21,22}$ In present study $23 \%$ had history of treatment taken for the infertility, family history of twinning was present in $9 \%$ cases while $8 \%$ cases conceived within 3 months of stoppage of OCP. Other factors like maternal height, weight and diet etc have not been considered in present study. Family history of twinning has been reported in $19 \%$ by chowdhury et al and $30 \%$ by Sultaria et al Twin after ovulation has been reported in $17 \%$ and $14 \%$ by Chowdhry and Sultana et al respectively.

Table 3 demonstrates the fetal presentation at delivery. Vertex-Vertex was found in $52.6 \%$ cases and VertexNonvertex in $17 \%$ cases (Vertex- Breech in $15.7 \%$ and Vertex-Transverse in $1.3 \%$ ) and Nonvertex presentation in $30 \%$ cases (Breech-Vertex 18.4\%, Breech Breech $12 \%)$. Shevernak et al and Chowdhury in therir studies found majority of foetal presentation as vertex-vertex in $42.5 \%$ ad $47.5 \%$ respectively followed by vertexnonvertex (38.4\% and $26.5 \%$ respectively). ${ }^{19,23}$

$30 \%$ patients delivered vaginally (includes spontaneous vaginal deliveries, instrumental deliveries and assisted breech deliveries) while $70 \%$ cases required LSCS commonest indication being mal-presentation. Study by Chowdhary et al and Sultana et showed rates of LSCS $49.1 \%$ and $56 \%$ respectively for twin pregnancies.

64 cases of twins gave birth to 128 babies, out of 128 babies $20.3 \%$ of $1^{\text {st }}$ twin had spontaneous vaginal delivery and $14 \%$ of $2^{\text {nd }}$ twin had spontaneous vaginal delivery. $4.6 \%$ of first twin were delivered by assisted breech and $7.8 \%$ of second twin had assisted breech delivery. Instrumental (Forcepts/Vacuum) was required in $6 \%$ cases of first twin and $7.8 \%$ cases of second twin. Number of assisted breech as well as instrumental delivery were more for $2^{\text {nd }}$ twin than $1^{\text {st }}$ twin, indicating more requirement of skilled techniques and maneuvours for delivering the second twin.

All cases of twins vaginal deliveries were conducted in operation theatre with keeping the facilities of c. section ready. In one case after vaginal delivery of first twin, $2^{\text {nd }}$ twin required LSCS in view of transverse lie with oligohydromnios making the internal podalic version difficult and the on call obstetrician preferred delivery by LSCS than IPV as a safe mode of delivery. Delivery of second baby in twin puts more challenges to the obstetrician in terms of skills and timely decision making as compared to delivery of first twin.

Preterm labour (56\%) was the commonest obstetric complication recorded in present study, followed by anaemia (43\%), incidence of pregnancy induced hypertension was significantly higher $(22 \%)$ in twin pregnancies, this has been attributed to higher maternal age at conception as well as exposure to superabundant chorionic villi in twin pregnancies. ${ }^{24}$

$28 \%$ cases didn't have any complication while rest had either one or two obstetrical high risk associated such as PROM (17\%), IUGR (13\%), placenta previa (9\%), abruption $(2 \%)$, polyhdromnios $(5 \%)$. Few patients had more than one obstetrical high risk associated such as placenta previa with IUGR etc. Hence the total number of complications are more than total number of cases studied. Other studies have also reported higher incidence of obstetrical complications with twins. ${ }^{25,26}$

Though there was no maternal mortality in our study, one patient following vaginal twin delivery had post-partum haemorrhage not responding to conservative medical management with oxytocics, required conservative surgery B-Lynch compression sutures with internal illiac ligation. It was nearly missed mortality with increased morbidity requiring blood transfusion, ICU care and prolong hospitalization. Previous studies of Chowdhaury and Sultana also did not report any maternal mortality, however one study done in Nigeria described maternal mortality of $2 \%$ for twin deliveries. ${ }^{19,25,27}$ Inspite of high association with maternal obstetrical complications zero maternal mortality could be due to tertiary care facilities with ICU, blood bank availability and skilled manpower to handle complication 24 hours.

$63(49 \%)$ and $65(51 \%)$ of twin births were males and females respectively giving male to female sex ratio of approximately $0.97: 1$. The sex combinations in twin deliveries were male-male in $18(28 \%)$, female-female 19 (29\%), male female 15 (23\%) and female-male $12(18 \%)$. Mutihir et al reported $54.7 \%$ of twin pregnancies to be boys, while Kavehmanesh et al reported $58.2 \%$ if babies were girls and $41.8 \%$ were boys. ${ }^{9,28}$ However Melamed et al and Chittachaoen et al indicated that female neonates are significantly more frequent in twin pregnancies. ${ }^{29,30}$ This may be due to tendency of genetically female zygotes for division or the nutritional and spatial limitations associated with the presence of multiple fetuses may reinforce this tendency. ${ }^{30}$

Placental examination of twin deliveries showed that 58 $(91 \%)$ dichorinoic-diamniotic, 4 (6\%) diamniotic monochorionic and $2(3 \%)$ were monochorinoic monoamniotic. According to Weinberg rule monozygotic twins and dizygotic twins constituted 16\% and $84 \%$ respectively in our study. This rule states that the number of monozygotic twins in a given twin population is the 
result of the total number of like sex twins minus unlike sex twins. The rule is based on the assumption that the total number of like sex dizygotic twins in a given large population of at least $1,00,000$ people in a community equals that of unlike sex dizygotic twins. Therefore, the excess of the total like sex twins over the total unlike sex twins will be due to monozygotic twins. ${ }^{31}$ The rate of monozygotic twins was lower in this study when compared to other studies. ${ }^{6,31}$ This difference may be explained by the different methods used to identify zygosity among different studies.

Out of total 128 neonates $9(7 \%)$ babies had APGAR score less than 7 at min., (APGAR $<7$ for $5 \%$ of twin 1 and $9 \%$ of twin 2) while $4 \%$ neonates had APGAR $<7$ at 5 min (APGAR $<7$ at 5 min in $1.5 \%$ twin 1 while $6 \%$ in twin 2) this reflects $2^{\text {nd }}$ baby is at high risk of asphyxia as compared to first twin. NICU was required in $47 \%$ of twins. NICU requirement was seen $36 \%$ for twin 1 and $58 \%$ for twin2. Previous studies by Chowdhary et al showed APGAR score $<7$ in $7.5 \%$ of first twins and $13 \%$ of second twins. ${ }^{19}$

Early perinatal mortality (within 7 days) was also higher for second baby of twin as compared to first twin. Overall 8 neonatal death among 128 neonates reported. 3\% of first twin and $9 \%$ of $2^{\text {nd }}$ twin had neonatal death within 7 days. There was no intrapartum still birth recorded in present study. Overall $37 \%$ of babies had birth weight more than $2.5 \mathrm{~kg}$. $41 \%$ of twin 1 and $33 \%$ of twin 2 had birth weight more than $2.5 \mathrm{~kg}$. $63 \%$ of total newborn in study had birth weight less than $2.5 \mathrm{~kg}, 59 \%$ of twin 1 and $67 \%$ of twin 2 had birth weight less than $2.5 \mathrm{~kg}$. Those weighing less than $2.5 \mathrm{~kg}$ were further sub-categorized as shown in table and most of the babies showed birth weight between $2-2.5 \mathrm{~kg}(33 \%)$, while $16 \%$ had birth weight between $1.5-2 \mathrm{~kg}$ and $10 \%$ were between $1-1.5 \mathrm{~kg}$ and $8 \%$ were below $1 \mathrm{~kg}$. These categories also showed twin 2 birth weight slightly lower than twin 1 .

Increased rate of perinatal death observed in twin pregnancies may be explained by the increased rate of intrauterine growth restrictions, premature rupture of membranes, preterm deliveries, low birth weight and low APGAR scores among twin deliveries. ${ }^{25,26}$ Prematurity is the leading cause of perinatal mortality in multiple pregnancy as was also revealed by studies of Koram et al and Ziadeh S..$^{32,33}$

This study may have its own limitation in that it was conducted in one referral hospital, where most of the laboring mothers come because of complications. This might have overestimated the incidence of twin pregnancy and will not represent the general population and home deliveries that need further community based studies. Also cases of twins with one twin having intrauterine death have been excluded and hence complications due to intrauterine death of other twins could not be obtained from this study.

\section{CONCLUSION}

Complications associated with higher order pregnancies cannot be prevented but can be detected early and controlled adequately by proper and prompt management. Regular and more frequent antenatal checkup, referral services to well equipped centres, liberal hospital admission policy and perform deliveries in well equipped centres under supervision are essential measures to reduce adverse pregnancy outcome. Periodic review about the perinatal statistics and prevalence of twin delivery is important to scale up the services required to reduce the perinatal mortality in twin deliveries.

This study addresses significant gap in the literature on the outcomes of twin deliveries in low and middle income countries, where frequency of twin birth is often high and epidemiological research on multiple birth is challenging. This study not only briefs about the perinatal outcome in twins but also identifies association of various factors with twin pregnancies such as Age, Parity, family history, OCP and ovulation inducing agents with twin gestation. It emphasizes the documentation and importance of the of twin birth registries in LMIC to have the periodic review of outcome in twins so as to scale up the efforts to give the best perinatal outcome and to reduce maternal and perinatal morbidity as well as morbidity.

\section{ACKNOWLEDGMENTS}

Authors would like to thank pathology and radiology department for providing necessary inputs of various data of twin related cases, authors are also thankful to medical superintendent Dr. Vinayak More and Medical Record Officer Dr. Shekhar Dhongade for permitting us to access the data of cases under study. Authors want to pay the gratitude to Dr. Vikas Chothe MD PSM (Ayu), statistician, all supervisors, data collectors and study participants for their manuscript review, cooperation and support.

\section{Funding: No funding sources Conflict of interest: None declared}

Ethical approval: The study was approved by the Institutional Ethics Committee

\section{REFERENCES}

1. Bakare A, Akinboro A, Azeez M. Frequency of twinning in southwest Nigeria. Indian J Human Genetics. 2008;14:41-47.

2. Dera A, Breborowiczg H, Keith L. Twin pregnancyphysiology, complications and the mode of delivery. Archives of Perinatal Medicine. 2007;13:1673-5.

3. Cunningham FG, Leveno KJ, Bloom SL, Hauth JC, Rouse DJ, et al. Williams Obstetrics. $23^{\text {rd }}$ ed. USA: McGraw-Hill;2010. 
4. Ananth CV, Chauhan SP Epidemiology of Twinning in Developed Countries. Seminars Perinatol. 2012;36:156-161.

5. Russell RB, Petrini JR, Damus K, Mattison DR, Schwarz RH. The changing epidemiology of multiple births in the United States. Obstet Gynecol. 2003;101(1):129-35.

6. Glinianala SV, Rankin J, Renwick M. Time trends in twin perinatal mortality in northern England, 198294. Northern region Perinatal Mortality Survey Steering Group. Twin Res. 1998;1(4):189-95.

7. Ananth CV, Smulian HC, Demissie K, Vintzileos AM, Kunppel RA. Placental abruption among singleton and twin births in the United states: risk factors profiles. Am J Epidemiol. 2001;153:771-8

8. Adinma JI, Agbai AO, Multiple birth in Nigerian Igbo women: incidence and outcomes $\mathrm{J}$ Obstet Gynaecol. 1997;17(1):42-44.

9. Mutihir JE, Pam VC. Obstetric outcome of twin pregnancies in Jos, Nigeria: a 16 month review in Jos University Hospital, Nigeria. Niger J Clin Pract. 2007; 10(1):15-18

10. Basirat Z, Hajiahmadi M. Comparison of maternal and fetal outcomes in twin and single pregnancy. Baol uni J. 1385;8(2):47-50.

11. Kavemanesh Z, Amirsalari S, Tokaman M. Frequency of multiple pregnancy and its outcomes in Tehran hospitals. Pediatrics Ir J. 1386;17:261-7.

12. Usta IM, Nassar AH, Awwad JT, Nakad TI, Khalil AM, Karam KS. Comparison of the perinatal morbidity and mortality of the presenting twin and its co-twin. J Perinatol. 2002 Aug 1;22(5):391-6.

13. Musilli F, Karanja J. Multi fetal pregnancies at a maternity hospital I Nairobi. East Afr Med J. 2009;86(4):162-5.

14. Jadranko S. Twin pregnancy in virovitica general hospital maternity ward. Gynaecologia et Perinatologia. 2006;15(4):205-11.

15. Sumathipala A, Siribaddana S, De SilvaN, Fernando D, Abeysingha N, Dayaratne R, et al. Srilankan Twin registry. Twin Res. 2002 Oct;5(5):424-6.

16. Smits J, Monden C. Twinning across the developing world. PLoS One. 2011 Sep 28;6(9):e25239.

17. Aisien AO, Olarewaju RS, Imade GE. Twins in Jos Nigeria: a seven-year retrospective study. Med Sci Monit. 2000 Sep-Oct;6(5):945-50.

18. Korsak VS. Incidence and some perinatal problems of multiple pregnancies in a central referral hospital, Addis Ababa. Ethiop Med J. 1989;27:217-221.

19. Chouwdhury S. Clinical Study on twin pregnancy, FCPS, Bangladesh College of Physicians and Surgeons. Dhaka;1998.

20. Spellacy WN, Handler A, Ferre CD. A case-control study of 1253 twin pregnancies from a 1982-1987 perinatal data base. Obstet Gynecol. 1990 Feb 1;75(2):168-71.

21. Onyiriuka AN. Twin delivery, comparison of incidence and fetal outcome in Health Institutions in Benin City, Nigeria. Nig Q J Hosp. Med. 2003;16(3):88-92.

22. Onwuzuruike BK, Onah HE. Caeserean section in twin pregnancies in Enugu, Nigeria. International $\mathrm{J}$ Med Health Dev. 2004;9(1):8-11.

23. Adams DM, Chervenak FA. Intrapartum management of twin gestation. Clin Obstet Gynecol. 1990 Mar 1;33(1):52-60.

24. Gary CF, Kenneth LJ, Steven BL, John HC, Larry G, Katharine WD, Multifetal Gestation. New York: Mc Graw-Hill Medical Publishing Division;2005:911948.

25. Senat MV, Ancel PY, Bouvier-colle MH, BrÉart G. How does multiple pregnancy affect maternal mortality and morbidity? Clin Obstet Gynecol. 1998 Mar 1;41(1):79-83.

26. Coonrod DV, Hickok DE, Zhu K, Easterling TR, Daling JR. Risk factors for pre-eclampsia in twin gestation- a population based cohort study. Obstet Gynecol. 1995;85:645-50.

27. Sultana H. Fetal and maternal outcome of twin pregnancy -A study of 50 cases, Bangladesh college of Physicians and Surgeons, Dhaka; 1998.

28. Kavemanesh Z,Amirsalari S, Torkaman M,et al. Frequency of multiple pregnancy and its outcomes in Tehran hospitals. Pediatr Ir J. 1386;17:261-7

29. Melamed N, Yogev Y, Glezrman M. Effect of fetal sex on pregnancy outcome in twin pregnancies. J Pak Med Assoc. 2002;52(4):143-7

30. Chittacharoen A, Singhkun D, Ayudhya N. Pregnancy outcome of twin pregnancy in Ramathibodi hospital. Med Assoc Thai. 2006;89(4):76.

31. Kullima A, Geidam A, Andu B. Outcome of twin deliveries at the University of Maiduguri Teaching Hospital: 5 year review. Nigerian J Clin Pract. 2011;14:345-348.

32. Koram L, Kamdom Moyo J. fetal risk factors in twin pregnancies,critical analysis of 265 cases. Rev Fr. Gynecol Obstet. 1995;90:55-62.

33. Ziadeh S. outcome of twin pregnancies in north Jordan. J Obstet Gynecol. 2000;20:492-4.

Cite this article as: Asalkar M, Kasar B, Dhakne S, Panigrahi PP. Study of perinatal outcome in twin gestation in rural referral hospital in Maharashtra (India): a cross sectional study. Int J Reprod Contracept Obstet Gynecol 2017;6:5074-80. 